\title{
Thermodynamic entropy of organic oxidation in the water environment: experimental evaluation compared to semi-empirical calculation
}

\author{
Li Luo ${ }^{1} \&$ Xiaochang C. Wang ${ }^{1, *} \&$ Huu Hao $\mathrm{Ngo}^{2} \&$ Wenshan $\mathrm{Guo}^{2}$ \\ ${ }^{1}$ International Science \& Technology Cooperation Center for Urban Alternative Water Resources \\ Development, Key Lab of Northwest Water Resource, Environment and Ecology, Ministry of Education, \\ Xi'an University of Architecture and Technology, Xi'an 710055, China \\ ${ }^{2}$ School of Civil and Environmental Engineering, Faculty of Engineering and Information Technology, \\ University of Technology, Broadway, Sydney, NSW 2007, Australia \\ *Corresponding author: Xiaochang C. Wang, xcwang@xauat.edu.cn
}

\begin{abstract}
Residual organic matters in the secondary effluent are usually less biodegradable in terms of the total organic carbon content, and when discharged into a receiving water body, their further decomposition most likely mainly occurs due to chemical oxidation. Using this scenario, a semiempirical method was previously developed to calculate the thermodynamic entropy of organic oxidation to quantitatively evaluate the impact of organic discharge on the water environment. In this study, the relationship between the entropy increase $(\Delta \mathrm{SC})$ and excess organic mass $(\triangle \mathrm{TOC})$ was experimentally verified via combustion heat measurement using typical organic chemicals and mixtures. For individual organic chemicals, a linear relationship was detected between $\triangle \mathrm{SC}$ and $\triangle \mathrm{TOC}$ with the same proportionality coefficient, $54.0 \mathrm{~kJ} / \mathrm{g}$, determined in the previous semi-empirical relationship. For the organic mixtures, a linear relationship was also identified; however, the proportionality coefficient was $69.2 \mathrm{~kJ} / \mathrm{g}$, indicating an approximately $28 \%$ increase in the oxidation heat required to decompose the same organic mass. This increase in energy can likely be attributed to the synergistic effects of hydrogen bonding, hydrophobic interactions, $\pi-\pi$ interactions, and van derWaals interactions between functional groups of different organic compounds. Intermolecular interactions may result in 17$32 \%$ more dissociation energy for organic mixtures compared to the organic components' chemical structures. Because organics discharged into a water body are always a mixture of organic compounds, the proportionality coefficient obtained using organic mixtures should be adopted to modify the previously proposed semi-empirical equation.
\end{abstract}

Keywords: Organics . Chemical oxidation . Entropy increase . Synergistic effects . Water environment 


\section{Introduction}

Effluent discharged from wastewater treatment plants (WWTPs) is the major source of organic matter in aquatic environments (Lee and Rasmussen 2006). The contribution of discharged organic matter to rivers and streams is particularly significant in the low-flow summer season, especially in arid areas where the discharged effluent may dominate the stream-flow during an extremely dry period (Quaranta et al. 2012). Therefore, there is an urgent need to quantitatively evaluate the impact of organic matter discharged from secondary effluent on the water environment.

Secondary effluent from a WWTP usually contains a relatively high concentration of COD that has not been effectively removed by a biological treatment process, such as the activated sludge process. This residual organic matter generally belongs to a less or non-biodegradable fraction (Katsoyiannis and Samara 2007). The residual organic concentration, in terms of total organic carbon (TOC), can be as high as 10 to $40 \mathrm{mg} / \mathrm{L}$ (Michael et al. 2015). In contrast, the biodegradable fraction is often very low in the secondary effluent, and the assimilable organic carbon (AOC) concentration may only be at $\mu \mathrm{g} / \mathrm{L}$ or even ng/L level (Pramanik et al. 2015; Thayanukul et al. 2013).

The direct impact of effluent discharge to a receiving water body is an increase in pollutant concentration in part of or in the whole water body. If pollutant loading does not exceed the carrying capacity of the water body, excess pollutants will be gradually removed through natural processes, leading to a recovery of water quality to its background level (Wang et al. 2015). Depending on the properties of the excess organic substances, self-purification may be achieved through biological actions to decompose biodegradable fractions following the Streeter-Phelps equation (Wang et al. 2015) or via chemical oxidations to decompose the non-biodegradable fractions (Gotovtsev 2010). Under natural conditions, the main pathways for the degradation of the less or non-biodegradable organic substances are oxidation assisted by solar radiation, called the photolysis process (Dong et al. 2015; Tijani et al. 2013). Through such kind of oxidation process, the bulk concentration of organic matter can eventually return to background levels. Therefore, it can be reasonably assumed that chemical oxidation might be the sole process responsible for the decomposition of excess organics from secondary effluent.

From the thermodynamic viewpoint, the degradation of excess organics by chemical oxidation would be accompanied by an irreversible energy dissipation. According to the Second Law of Thermodynamics, entropy can be used to determine the irreversibility of a thermodynamic process (Atkins and de Paula 2002). The reaction of organic matter decomposition in surface water is considered to occur under constant pressure (atmospheric pressure, if the influence of water depth is ignorable) in a closed system, so a series of irreversible reactions for the decomposition of pollutants will cause the entropy to increase. Consequently, the entropy increase $(\Delta S)$ can be used to directly and quantitatively evaluate the impact of organic matter discharged into the water environment. However, few studies have reported entropy increases in aquatic systems due to the intrusion of organic pollutants.

For a chemical reaction under constant pressure, if the work done on the system simply results in an expansion of the volume, the heat of the reaction $(\Delta Q)$ is numerically equal to the enthalpy change of the reaction $(\Delta \mathrm{rH})$ but with the opposite sign $(-)$. Therefore, $\Delta \mathrm{rH}$ can be used as a 
surrogate parameter for $\Delta \mathrm{Q}$ in the $\Delta \mathrm{S}$ calculation (Lukas et al. 2007). For organic substances of known molecular structures, $\Delta \mathrm{rH}$ can be theoretically calculated according to the oxidation reactions, which results in complete decomposition to $\mathrm{CO}_{2}, \mathrm{H}_{2} \mathrm{O}$, and other simple inorganic elements. When a water body receives excess organic pollutants, the endpoint is the return of the organic carbon concentrations to their background level, as long as the pollutant loading does not exceed the carrying capacity of the water body. This is equivalent to the complete oxidation of excess organic pollutants. In addition, the oxidation process for excess organics is also accompanied by energy consumption, thereby increasing the entropy of the water body, a higher energy consumption will result in a higher entropy increase. As complete oxidation of organics requires the highest level of energy consumption, the endpoint of oxidation is supposed to be the complete removal of excess organics from the water body (Matilainen and Sillanpää 2010). Following the thermodynamic principle, the $\Delta \mathrm{rH}$ calculation can be conducted by taking into account the initial state (intrusion of excess organics) and the final state (recovery to the background condition) without considering the detailed reaction pathways.

Under the assumption that excess organic pollutants were completely decomposed by chemical oxidation, more than 200 organic substances with known molecular structures were used to calculate the standard molar enthalpy change of the reaction $\left(\Delta \mathrm{rH}^{0}\right)$ (Luo et al. 2012). As a result, a proportional relationship was found between the calculated $\Delta \mathrm{rH}^{0}$ values and the TOC content, and the proportionality coefficient was determined to be $54.0 \mathrm{~kJ} / \mathrm{g}$. On this basis, a semiempirical relationship was obtained to calculate the entropy increase $\Delta \mathrm{Sc}$ due to excess organic decomposition. Using this semiempirical relationship, it is possible to evaluate the impact of effluent discharge on the water environment based on $\triangle$ TOC. However, such a simple method has not been experimentally verified. Because the final products of complete oxidation for each organic substance are the same as those in a combustion reaction, the heat produced by complete oxidation is equal to the combustion heat. In this case, the calculated $\Delta \mathrm{rH} 0$ can be verified by a heat of combustion measurement. Under the same assumption, several typical organic chemicals with known structures can be selected to measure both the combustion heat $\Delta \mathrm{Q}$ and TOC, and a relationship between $\Delta \mathrm{Q}$ and TOC can be established. However, the composition of organic substances in the secondary effluent varies with the content of the organic components. There are different major components in the different secondary effluent streams, including alkanes, organic acids, esters, alcohols, amides, proteins, fats, and oils (Wang et al. 2014). It is difficult to measure the combustion heat of the organic substances in the secondary effluent because of its complicated composition, which was sometimes unable to be separated from the secondary effluent. On the other hand, excess organics due to effluent discharge are in fact organic mixtures, and there may inevitably exist interactions between different organic molecules that have not been taken into account in this calculation. Thus, to simulate organic compounds in the secondary effluent, organic mixtures with a broad range of carbon contents have been prepared based on the organic chemicals that commonly exist in the secondary effluent. To develop a $\Delta \mathrm{Sc}$ method that is more suitable for practical use, this study was conducted to experimentally verify the $\Delta \mathrm{Sc}$ $\triangle \mathrm{TOC}$ relationship and to illuminate the mixture effects between different organics.

\section{Materials and methods}




\section{Chemicals}

\section{Organic chemicals}

Organic compounds are normally composed of carbon, hydrogen, and oxygen, as well as nitrogen and sulfur. In natural water and the secondary effluent, they may include pure hydrocarbons and organic compounds containing additional elements. Common additional elements are oxygen and nitrogen, with structures varying form linear and branched to ring groups (Xue et al. 2011). In this study, several typical organic chemicals were selected to cover a range of different organic elements $(\mathrm{C}, \mathrm{H}, \mathrm{O}$, and $\mathrm{N})$ so that the combustion heat measurements could be more comprehensive. Furthermore, the selected chemicals contained a broad range of carbon content with structures of linear, branched, and ring groups; this was critical to capture because of the semi-empirical relationship calculated using these organic substances. As the TOC was used to quantify the organic mass, the selected chemicals also had to be soluble. Therefore, five organic chemicals from the lowest carbon content (methanol) to the highest carbon content (n-dodecane) were finally selected, as shown in Fig. 1. These chemicals can be classified into four types, namely pure hydrocarbons with only $\mathrm{C}$ and $\mathrm{H}$; compounds with $\mathrm{C}, \mathrm{H}$ and $\mathrm{O}$; compounds with $\mathrm{C}$, $\mathrm{H}$ and $\mathrm{N}$; and compounds with $\mathrm{C}, \mathrm{H}, \mathrm{O}$, and $\mathrm{N}$. For all of the selected organic chemicals, the theoretical organic carbon (ThOC) and standard molar enthalpy change of reaction $\left(\Delta \mathrm{rH}^{0}\right)$ were first calculated, and then, the TOC and corresponding combustion heats were measured. The selected organic chemicals are n-dodecane $\left(\mathrm{C}_{12} \mathrm{H}_{26}\right)$, methanol $\left(\mathrm{CH}_{4} \mathrm{O}\right)$, isopropyl alcohol $\left(\mathrm{C}_{3} \mathrm{H}_{8} \mathrm{O}\right)$, triethylamine $\left(\mathrm{C}_{6} \mathrm{H}_{15} \mathrm{~N}\right)$, and morpholine $\left(\mathrm{C}_{4} \mathrm{H}_{9} \mathrm{NO}\right)$. Among them, methyl alcohol and isopropyl alcohol belong to the type of compounds with $\mathrm{C}, \mathrm{H}$, and $\mathrm{O}$, while the chemical structure of isopropyl alcohol is more complicated than that of methyl alcohol. Morpholine has $\mathrm{C}$, $\mathrm{H}, \mathrm{O}$, and $\mathrm{N}$, with a ring group structure. All of these chemicals are of analytical grade or chromatographic grade (purity $\geq 99 \%$ ).<smiles>CCCCCCCCC</smiles>

n-Dodecane<smiles>CC(C)O</smiles>

Isopropyl alcohol

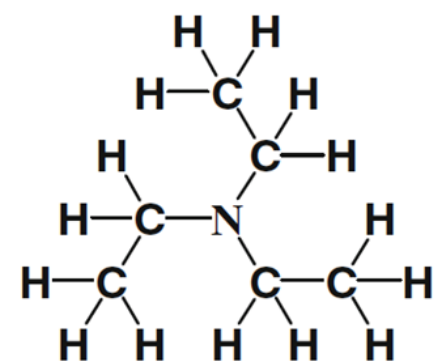

Triethylamine<smiles>CO</smiles>

Methanol

Fig. 1 Structural formulae for 5 organic chemicals<smiles>C1CNCCOC1</smiles>

Morpholine 
Secondary effluent from biological wastewater treatment still contains a certain amount of organic compounds, and the effluent TOC concentrations typically range between 10 and 50 $\mathrm{mg} / \mathrm{L}$. Dissolved organic matter (DOM) in the secondary effluent is a heterogeneous mixture of aromatic and aliphatic hydrocarbon structures that have attached amide, carboxyl, hydroxyl, ketone, and various other minor functional groups (Leenheer and Croué 2003). These organic compounds mainly consist of low molecular weight (smaller than $1000 \mathrm{Da}$ ) organic components, including humic substances, proteins, lipids, carboxylic acids, saccharides, amines, amino acids, and hydrocarbons (Shon et al. 2006; Xue et al. 2011). Therefore, to simulate organic compounds in secondary effluent, in this study, some liquid reagents of pure organic substances, which contain most of the organic components, were selected for mixing. Meeting the requirements for combustion heat and TOC analysis, these organic substances include alkyls, olefins, alcohols, acids, ethers, esters, ketones, benzenes, amines, nitro-compounds, ring compounds, and organic compounds containing sulfur or phosphorus. They can also be classified into the 4 types of organic chemicals and contained different numbers of carbon elements. Most of these organics are less or non-biodegradable, which can be commonly detected in secondary effluent. However, to cover a broad range of carbon contents, several organic chemicals with a low carbon content, such as methyl alcohol, formic acid, and methylamine, were also added to the mixture. According to the different components and proportions of the pure organic substances shown in Table 1, six organic mixtures were obtained. These six organic mixtures were selected to determine the combustion heat and corresponding TOC concentration.

Table 1 Components of organic mixtures

\begin{tabular}{|c|c|c|c|c|c|c|}
\hline \multirow[t]{2}{*}{ Organic substance } & \multicolumn{6}{|c|}{ Ratio of the organic substance (\%) } \\
\hline & Mixture 1 & Mixture 2 & Mixture 3 & Mixture 4 & Mixture 5 & Mixture 6 \\
\hline$n$-Dodecane & & & 12.5 & 18.75 & 18.75 & \\
\hline$n$-Hexadecane & & & & & & 12.5 \\
\hline Nitromethane & 87.5 & & & & & \\
\hline Methyl alcohol & & 93.75 & & & & \\
\hline Dehydrated alcohol & & & 6.25 & 12.5 & 6.25 & \\
\hline Formic acid & & 6.25 & & & & \\
\hline Lactic acid & & & 18.75 & 18.75 & 18.75 & \\
\hline 2-Propenoic acid & & & & & & 12.5 \\
\hline Triethyl phosphate & & & 12.5 & 12.5 & 12.5 & 6.25 \\
\hline Diethyl phthalate & & & & & & 12.5 \\
\hline 2-Ethoxyethanol & & & 6.25 & 6.25 & 6.25 & 6.25 \\
\hline Cyclohexanone & & & 6.25 & 6.25 & 6.25 & 6.25 \\
\hline Methylamine & 12.5 & & & & & \\
\hline Formamide & & & 25 & & & \\
\hline$N, N$-Dimethyl formamide & & & & 18.75 & 6.25 & 6.25 \\
\hline Triethanolamine & & & & & & 6.25 \\
\hline Aniline & & & & & 18.75 & 18.75 \\
\hline Morpholine & & & & & & 6.25 \\
\hline Dimethyl sulfoxide & & & 12.5 & 6.25 & 6.25 & 6.25 \\
\hline
\end{tabular}




\section{Experiments}

\section{Combustion heat measurement}

The combustion heats of the samples were measured using an RBC - II type rotating-bomb calorimeter (Yang et al. 2002). The calorimeter was calibrated with benzoic acid of $99.999 \%$ purity, which has a standard heat of combustion of $-26,434 \mathrm{~J} / \mathrm{g}$ at $298.15 \mathrm{~K}$. The experimental procedures were nearly the same as those outlined by Yang et al. (2002). The initial temperature and oxygen pressure of the combustion reaction were regulated to $298.15 \pm 0.01 \mathrm{~K}$ and $2.5 \mathrm{MPa}$, respectively. A digital indicator for the temperature measurement was used to ensure better precision and accuracy during the experiment. The calibrated experimental result for the energy

equivalent of the calorimeter (W) was $18,604.99 \pm 8.14 \mathrm{~J} / \mathrm{K}$ with a precision of $4.38 \times 10^{-4}$. The samples' combustion heats were determined using the calorimeter, which had been calibrated with benzoic acid. Each sample was placed into a capsule with a combustion energy of 46,627.59 $\mathrm{J} / \mathrm{g}$ at $298.15 \mathrm{~K}$. The determination method was the same as that for calibrating the calorimeter with benzoic acid. The combustion heats of the samples were measured by six experiments. The values were calculated using Eq. (1):

$$
-\Delta \mathrm{Q}=\frac{\mathrm{W} \Delta T-\mathrm{Gb}-5.983 \mathrm{c}-\mathrm{qm}}{\mathrm{m}}
$$

where $\Delta \mathrm{Q}$ denotes the combustion heat of samples $(\mathrm{J} / \mathrm{g}), \mathrm{W}$ is the energy equivalent of the $\mathrm{RBC}$ - II type rotatingbomb calorimeter $(\mathrm{J} / \mathrm{K}), \Delta \mathrm{T}$ is the calibrate value of the temperature rise $(\mathrm{K}), \mathrm{G}$ is the combustion enthalpy of $\mathrm{Ni}-\mathrm{Cr}$ wire for ignition $(0.9 \mathrm{~J} / \mathrm{cm}), \mathrm{b}$ is the length of the actual Ni-Cr wire consumed $(\mathrm{cm}), 5.983$ is the formation enthalpy and solution enthalpy of nitric acid corresponding to $1 \mathrm{~mL}$ of $0.1000 \mathrm{~mol} / \mathrm{L}$ solution of $\mathrm{NaOH}(\mathrm{J} / \mathrm{mL}), \mathrm{c}$ is the volume of 0.1000 $\mathrm{mol} / \mathrm{L}$ solution of $\mathrm{NaOH}$ consumed $(\mathrm{mL}), \mathrm{q}$ is the combustion energy of the capsule $(46,627.59$ $\mathrm{J} / \mathrm{g}$ ), and $\mathrm{m}$ is the mass of the sample $(\mathrm{g})$.

\section{TOC analysis}

TOC analyses of samples were executed according to the thermal catalytic oxidation principle using a Shimatzu TOC - VCPH analyzer. The organic chemicals and organic mixtures were diluted 10,000 times in pure water before TOC analysis was performed.

\section{Calculation methods}

The organic components in the mixtures contain the elements of carbon, hydrogen, oxygen, nitrogen, and sulfur, so a general molecular formula of $\mathrm{C}_{\mathrm{x}} \mathrm{H}_{\mathrm{y}} \mathrm{O}_{\mathrm{z}} \mathrm{N}_{\mathrm{t}} \mathrm{S}_{\mathrm{m}}$ can be utilized to represent all of the organic substances. Considering a state where each organic substance is completely decomposed into the simplest form of inorganic substances by chemical oxidation, forming $\mathrm{CO}_{2}$ (g), $\mathrm{H}_{2} \mathrm{O}(\mathrm{l}), \mathrm{N}_{2}(\mathrm{~g})$, and $\mathrm{SO}_{2}(\mathrm{~g})$, the chemical reaction for its complete oxidation can be written in a general equation as follows:

$$
\begin{aligned}
\mathrm{C}_{x} \mathrm{H}_{y} \mathrm{O}_{z} \mathrm{~N}_{t} \mathrm{~S}_{m}+(x+y / 4+m-z / 2) \mathrm{O}_{2} \rightarrow x \mathrm{CO}_{2} \\
+y / 2 \mathrm{H}_{2} \mathrm{O}+t / 2 \mathrm{~N}_{2}+m \mathrm{SO}_{2}
\end{aligned}
$$


The standard molar enthalpy change of reaction $\Delta \mathrm{rH} 0(\mathrm{~kJ} / \mathrm{mol})$ for Eq. (2) can be calculated (Atkins and de Paula 2002) as:

$\Delta_{\mathrm{r}} \mathrm{H}^{0}=\sum \mathrm{v}_{\text {prod }} \Delta_{\mathrm{f}} \mathrm{H}_{\text {prod }}^{0}-\sum \mathrm{v}_{\text {react }} \Delta_{\mathrm{f}} \mathrm{H}_{\text {react }}^{0}$

where $v_{\text {prod }}$ and $v_{\text {react }}$ are the stoichiometric coefficients of each product and reactant from Eq. (2),

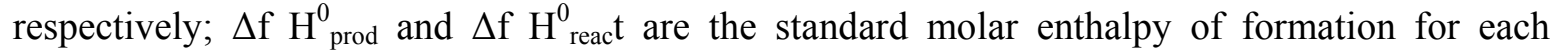
product and each reactant from the thermodynamic data base (Atkins and de Paula 2002) (kJ/mol).

Therefore, the theoretical reaction heat values $\Delta \mathrm{rH}^{0}$ of the individual organic chemicals can be calculated with Eq. (3) using the stoichiometric coefficients for the reactants and products from Eq. (2) and the standard molar enthalpy of formation for each reactant and product derived from the thermodynamic database. Regarding the interaction between chemicals to be ignored, the theoretical reaction heat of six organic mixtures can be obtained by different proportions of the individual organic substances and their related $\Delta \mathrm{rH}^{0}$. Therefore, the theoretical reaction heat of organic mixtures $\Delta \mathrm{rH}_{\mathrm{m}}^{0}(\mathrm{~kJ} / \mathrm{L})$ can be calculated as:

$$
\Delta_{r} H_{\mathrm{m}}^{0}=\sum_{i=1}^{16} r_{i} \cdot \frac{\Delta_{r} H_{\mathrm{i}}^{0}}{M i} \cdot \rho_{i}
$$

where $r_{i}$ is the ratio of organic substance $i$ in the mixture as shown in Table $1, \Delta \mathrm{rH}^{0}{ }_{i}$ is the standard molar enthalpy change of reaction for organic substance $\mathrm{i}(\mathrm{kJ} / \mathrm{mol}), \mathrm{M}_{\mathrm{i}}$ is the molecular mass of organic substance $i(g / \mathrm{mol})$, and $\rho_{i}$ is the density of organic substance $i(g / L)$.

\section{Results and discussion}

\section{Combustion heats and organic contents of individual organic chemicals and organic mixtures}

Based on the experimental data of combustion heat, the corresponding combustion heat for the five individual organic chemicals $\left(\Delta \mathrm{Q}_{\mathrm{i}}\right)$ and for the six organic mixtures $\left(\Delta \mathrm{Q}_{\mathrm{m}}\right)$ were calculated according to Eq. (1) as well as the corresponding density of the organic substances. The results of the measured combustion heat were regarded as the measured $\Delta \mathrm{rH}^{0}$. The mean results of the combustion heat for n-dodecane, triethylamine, morpholine, isopropyl alcohol, and methyl alcohol were $34,694.2,29,267.1,29,363.3,25,418.7$, and $16,977.3 \mathrm{~kJ} / \mathrm{L}$, respectively. The corresponding relative standard deviations were $0.14,0.13,0.09,0.12$, and $0.13 \%$, respectively. For the organic mixtures, the mean results for the combustion heat for mixtures 1 to 6 were $17,542.7,21,892.5,31,398.4,36,880.7,38,447.3$ and $43,703.7 \mathrm{~kJ} / \mathrm{L}$, respectively. The corresponding relative standard deviations were $0.17,0.17,0.12,0.120 .13$, and $0.11 \%$, respectively.

\section{Comparison of combustion heat values with theoretical reaction heat values}

Using Eq. (2) and Eq. (3), the theoretical reaction heat values of n-dodecane, triethylamine, morpholine, isopropyl alcohol, and methyl alcohol were calculated to be 7901.7, 4377.1, 2673.6, 2006.9, and $725.7 \mathrm{~kJ} / \mathrm{mol}$, respectively, according to their molecular structures and oxidation 
reactions. By plotting the measured and theoretical $\Delta \mathrm{rH}^{0}$ versus theoretical organic carbon (ThOC), Fig. 2 shows the relationship between the theoretical and measured $\Delta \mathrm{rH}^{0}$. Also shown in Fig. 2, the measured $\Delta \mathrm{rH}^{0}$ (i.e., $\Delta \mathrm{Q}_{\mathrm{i}}$ ) and theoretical $\Delta \mathrm{rH}^{0}$ for the five individual organic chemicals with different structures are well concentrated along the bisection line. This indicated an almost equal-value relationship between $\Delta \mathrm{Q}_{\mathrm{i}}$ and the theoretical $\Delta \mathrm{rH}^{0}$, so it is feasible to substitute the theoretical reaction heat with the measured combustion heats for pure organic chemicals.

Referring to the six organic mixtures listed in Table 1, the theoretical $\Delta \mathrm{rH}^{0}$ for each organic component can be calculated in the same manner as that of the pure organic chemicals. Then, based on the theoretical $\Delta \mathrm{rH}^{0}$ of each organic component and Eq. (4), the value of $\Delta \mathrm{rH}_{\mathrm{m}}^{0}(\mathrm{~kJ} / \mathrm{L})$ can be calculated. Table 2 shows the difference between the experimental combustion heats and theoretical reaction heats of the six organic mixtures. The value of the experimental combustion heat is larger than that of the theoretical reaction heat, and except for mixture 5, the difference $\left(-\Delta \mathrm{Q}_{\mathrm{m}}\right)$ and $\left(-\Delta \mathrm{rH}_{\mathrm{m}}^{0}\right)$ increased when the TOC concentration was also increased.

Table 2 shows that there are certain differences between the measured combustion heat and theoretical reaction heat calculated for each mixture. A possible reason for this difference may be the non-covalent interactions between different organic chemicals in the mixture that cannot be accounted for in the theoretical calculation. There should be two types of non-covalent interactions, one as the weak hydrophobic force (van der Waals, $\pi-\pi, \mathrm{CH}-\pi$ ) and hydrogen bonds, and another as the electrostatic linkages due to charge transfer, ion exchange, or ligand exchange (Mazzei and Piccolo 2015). Leenheer and Croué (2003) discovered that molecular structures can be formed by hydrogen bonding, nonpolar interactions, and polyvalent cation interactions. Gadad et al. (2007) reported that interactions between DOM and aromatic compounds are controlled by both $\pi-\pi$ interactions and hydrophobic interactions. Therefore, a variety of molecular interactions, such as hydrophobic interactions, $\pi-\pi$ interactions, hydrogen bonding, and van der Waals interactions, have been suggested to occur in organic compounds (Wang and Zhang 2014). For organic mixtures, one or more of the above-mentioned molecular interactions could form between different organic compounds, thus affecting the reactivity of organic compounds and increasing the energy requirement for organic mixture destruction. A more detailed comparison of the actual combustion heat and theoretical reaction heat for the mixtures will be given in "Estimating the additional dissociation energies between chemical molecules in the organic mixture".

Table 2 Measured TOC, experimental combustion heat $\left(-\Delta \mathrm{Q}_{\mathrm{m}}\right)$, and theoretical reaction heat $\left(-\Delta_{\mathrm{r}} \mathrm{H}_{\mathrm{m}}^{0}\right)$ of 6 organic mixtures

\begin{tabular}{lllll}
\hline Organic substances & $\begin{array}{l}\text { Measured } \\
\text { TOC, } \mathrm{g} / \mathrm{L}\end{array}$ & $\begin{array}{l}\text { Experimental combustion } \\
\text { heat, } \mathrm{kJ} / \mathrm{L}\end{array}$ & $\begin{array}{l}\text { Theoretical reaction } \\
\text { heat, } \mathrm{kJ} / \mathrm{L}\end{array}$ & $\begin{array}{l}\text { Difference between }\left(-\Delta \mathrm{Q}_{\mathrm{m}}\right) \\
\text { and }\left(-\Delta_{\mathrm{r}} \mathrm{H}_{\mathrm{m}}{ }^{0}\right), \mathrm{kJ} / \mathrm{L}\end{array}$ \\
\hline Mixture 1 & 228.2 & $17,542.70 \pm 29.87$ & $14,408.07$ & $3104.1-3164.5$ \\
Mixture 2 & 305.0 & $21,892.49 \pm 36.98$ & $17,195.54$ & $4660.0-4733.9$ \\
Mixture 3 & 455.4 & $31,398.35 \pm 38.05$ & $23,450.69$ & $7909.6-7985.7$ \\
Mixture 4 & 510.9 & $36,880.66 \pm 42.99$ & $26,472.71$ & $10,365.0-10,450.9$ \\
Mixture 5 & 570.1 & $38,447.31 \pm 48.86$ & $28,824.23$ & $9574.2-9671.9$ \\
Mixture 6 & 649.7 & $43,703.67 \pm 47.99$ & $30,571.80$ & $13,083.9-13,179.9$ \\
\hline
\end{tabular}




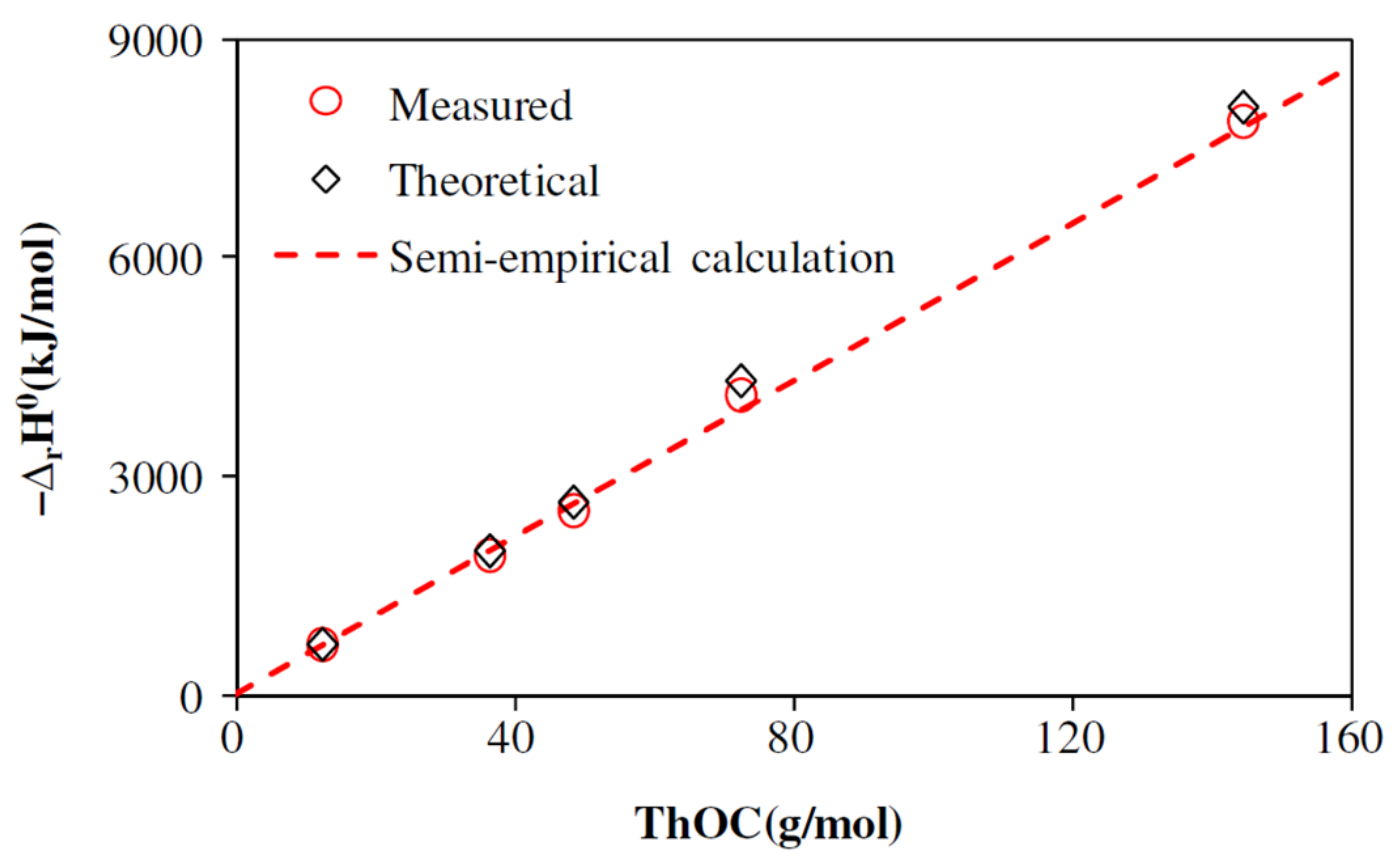

Fig. 2 Relationship between theoretical and measured combustion heats of 5 organic chemicals

\section{Thermodynamic entropy calculated based on combustion heat}

In this study, the chemical equation of oxidation for each organic substance is the same as the equation of combustion, so the heat of chemical oxidation is equal to the heat of combustion. The thermodynamic entropy can be evaluated using a combustion heat $(\Delta \mathrm{Q})$ analysis.

Based on the semi-empirical calculation of $\Delta \mathrm{Sc}$, as shown in our previous study (Luo et al., 2012), the semi-empirical equation for the reaction heat $\Delta \mathrm{rH}^{0}$ se $(\mathrm{kJ} / \mathrm{L})$ of organic compounds produces $-\Delta \mathrm{rH}_{\mathrm{se}}^{0}=\mathrm{k}^{\prime} / \mathrm{TOC}=54.0 \mathrm{TOC}$. For the theoretical methodology shown in Eq. (4), the organic components and proportions of the organic mixtures were needed for the calculation of reaction heat. However, for the semi-empirical methodology, the reaction heat of organic mixtures can be calculated by TOC values. Figure 3 shows the relationship between the measured combustion heats $\left(-\Delta \mathrm{Q}_{\mathrm{i}}\right)$ and semi-empirical equation of reaction heat $\left(-\Delta \mathrm{rH}_{\mathrm{se}}^{0}\right)$ for five individual organic chemicals. In Fig. 3 , the values of $-\Delta \mathrm{Q}_{\mathrm{i}}$ are well concentrated along the dotted line of $-\Delta \mathrm{rH}_{\mathrm{se}}^{0}=$ 54.0TOC. Due to the limitations of the combustion heat and TOC analyses, it is impossible to measure the entire organic substances collection to build the semi-empirical equation. Although five organic chemicals represent a limited selection, they contained all of the basic organic elements and different structures and were selected from within the same range of ThOC. Thus, the semi-empirical equation of reaction heat is suitable for the individual organic chemicals. It is demonstrated that the $\Delta \mathrm{Sc}$ calculation can successfully be applied to the individual organic compounds. 


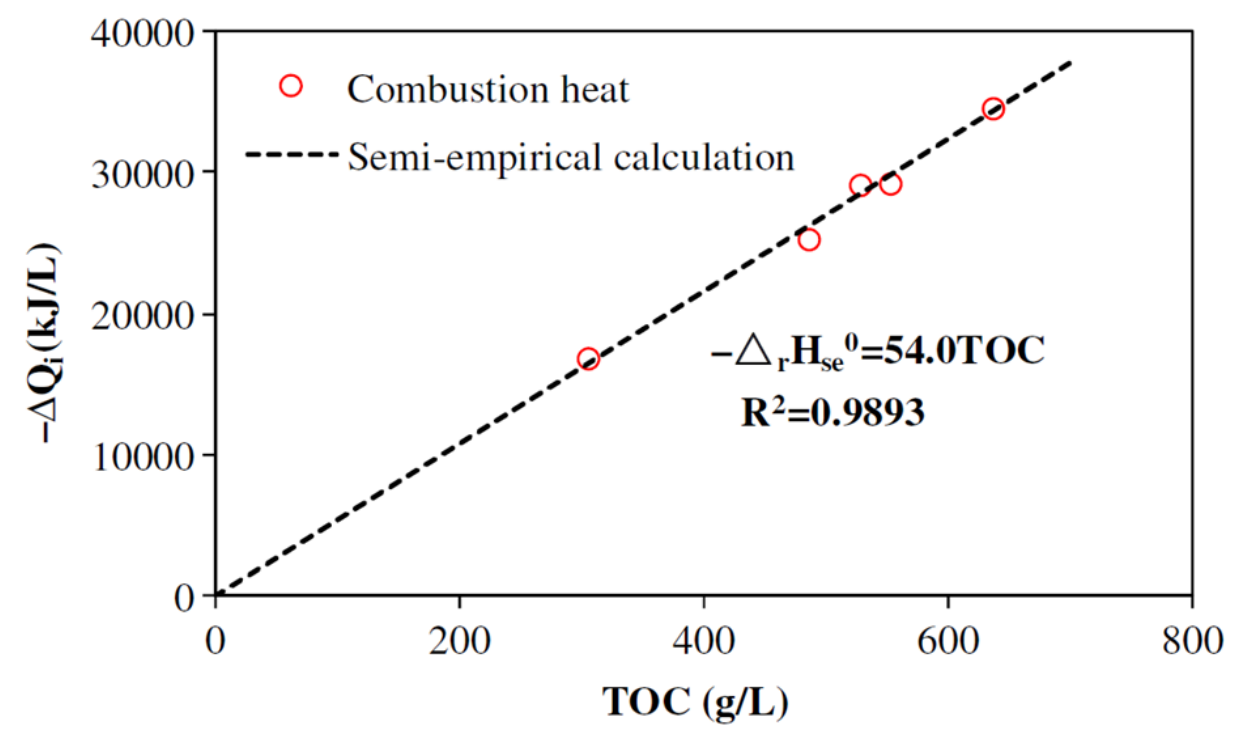

Fig. 3 Relationship between measured combustion heats and semiempirical calculation of reaction heat for 5 individual organic chemicals

Figure 4 shows the relationship between the experimental combustion heat $\left(-\Delta Q_{m}\right)$, theoretical reaction heat $-\Delta \mathrm{rH}^{0}{ }_{\mathrm{m}}$, and semi-empirical reaction heat $-\Delta \mathrm{rH}^{0}$ se of the six organic mixtures. As illustrated in Figs. 3 and 4, it is evident that the combustion heat increases with the organic carbon content, regardless of the organic chemicals or organic mixtures. Moreover, a proportional relationships exists between $-\Delta \mathrm{Q}_{\mathrm{m}}$, as well as $-\Delta \mathrm{rH}^{0}{ }_{\mathrm{m}}$, and the TOC concentration with a large proportionality coefficient of $-\Delta \mathrm{Q}_{\mathrm{m}}$ (Fig. 4). Although there is a small difference between $-\Delta \mathrm{rH}^{0}$ $\mathrm{m}$ and the corresponding value of $-\Delta \mathrm{rH}^{0}$ se, the values of $-\Delta \mathrm{rH}_{\mathrm{m}}^{0}$ were still well concentrated along the line of semi-empirical equation $-\Delta \mathrm{rH} 0 \mathrm{se}=54.0 \mathrm{TOC}$, as shown in Fig. 4. This indicated that the interaction between chemical molecules in the organic mixture could also be ignored in the $\Delta \mathrm{Sc}$ calculation.

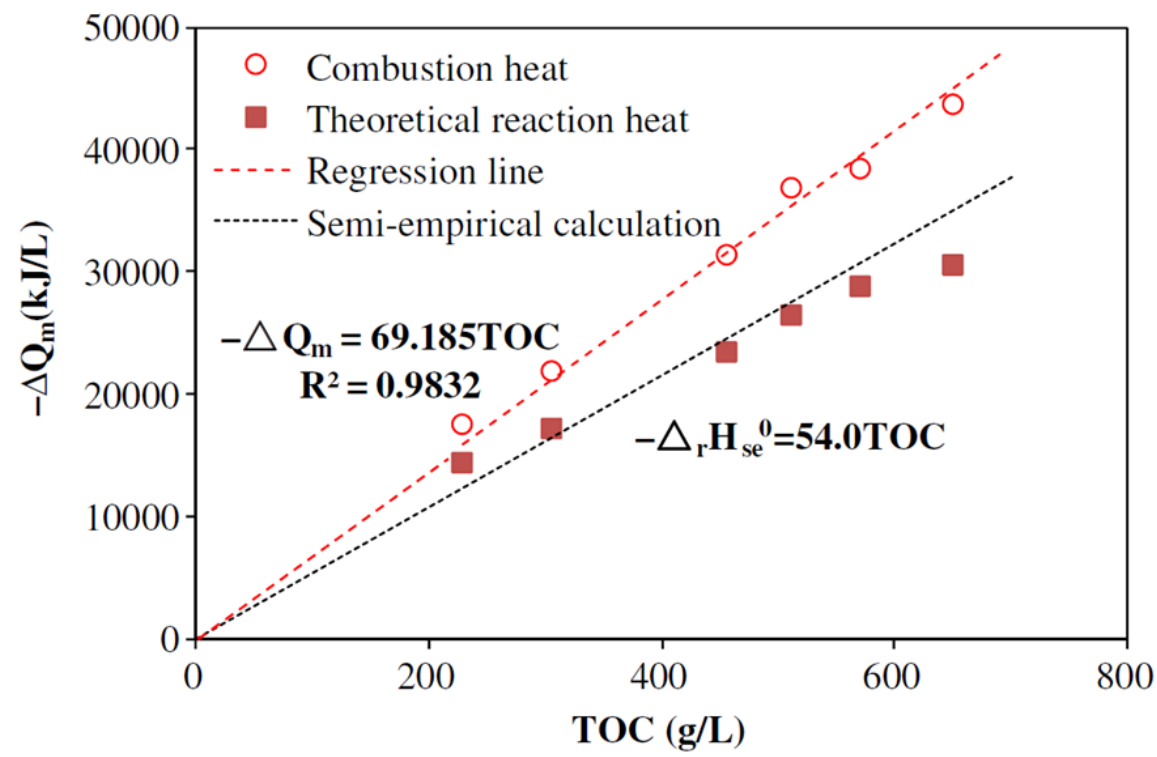

Fig. 4 Relationship between experimental combustion heats, theoretical and semi-empirical reaction heats of 6 organic mixtures 
For the six organic mixtures, Fig. 4 shows the proportional relationship between TOC and $-\Delta \mathrm{Q}_{\mathrm{m}}$. Using a correlative calculation, the linear proportional relationship appears as:

$$
-\Delta \mathrm{Q}_{\mathrm{m}}=k_{m} \cdot \text { TOC }\left(R^{2}=0.9832\right)
$$

The highly correlative relationship between TOC and $-\Delta \mathrm{Q}_{\mathrm{m}}$ indicates that TOC can be used as a parameter for an approximate estimation of the $\Delta \mathrm{Q}_{\mathrm{m}}$ value. According to the Second Law of Thermodynamics (Atkins and de Paula 2002), the entropy change of a chemical reaction under constant temperature is the amount of heat change $(\Delta \mathrm{Q})$ divided by the absolute temperature $(\mathrm{T})$. Thus, considering that the termination of organic decomposition is to the background level of $\mathrm{TOC}_{0}$, the entropy increase of the organic decomposition via chemical oxidation due to secondary effluent discharge can be calculated as:

$$
\Delta S_{C}^{\prime}=\frac{k_{m} \cdot \Delta \mathrm{TOC} \cdot V}{T}
$$

where $\mathrm{k}_{\mathrm{m}}=69.185 \mathrm{~kJ} / \mathrm{g}, \Delta \mathrm{TOC}$ is the reduced concentration of the total organic carbon from the secondary effluent $\left(\mathrm{g} / \mathrm{m}^{3}\right)$, and $\mathrm{V}$ is the volume of the secondary effluent discharge $\left(\mathrm{m}^{3}\right)$.

The organic matter residual in the secondary effluent can be regarded as an organic mixture. Therefore, as long as the organic mass can be measured as TOC, Eq. (6) can be used to evaluate the impact of effluent discharge on the receiving water body in terms of $\Delta \mathrm{S}^{\prime} \mathrm{c}$. For example, wastewater treatment needs to be upgraded to reduce pollutant loading to the aquatic environment in China and other countries (Logar et al. 2014). Using Eq. (6), a reduction of TOC by $1 \mathrm{mg} / \mathrm{L}$ is equivalent to a reduction of $\Delta \mathrm{S}^{\prime} \mathrm{c}$ by $232 \mathrm{~J} / \mathrm{K} \cdot \mathrm{m} 3$ under the assumption of $\mathrm{T}=298.15 \mathrm{~K}\left(25^{\circ} \mathrm{C}\right)$. For a domestic wastewater treatment plant with a capacity of $1.0 \times 10^{5} \mathrm{~m}^{3} /$ day, when advanced treatment, such as carbon adsorption is applied, an additional TOC reduction of 4 to $5 \mathrm{mg} / \mathrm{L}$ can often be obtained (Wei et al. 2009). In this case, the net benefit can be evaluated as approximately $1.0 \times 10^{5} \mathrm{~kJ} / \mathrm{K}$, indicating a remarkable reduction of the impact on the receiving water body.

\section{Estimating the additional dissociation energies between chemical molecules in the organic mixture}

For chemical mixtures, the reaction heat can be obtained either by semi-empirical calculation, $-\Delta \mathrm{rH}_{\mathrm{se}}^{0}=54.0 \mathrm{TOC}$, or by measurement, $-\Delta \mathrm{Q}_{\mathrm{m}}=69.185 \mathrm{TOC}$, where themeasured value provides an approximately $28 \%$ increase in the heat required to decompose the same organic mass. Mixing chemicals with different and complex molecular structures leads to various intermolecular interactions. Because the interaction energy between different organic molecules in the mixture could not be accounted for in the semi-empirical calculation, it was inevitable to underestimate the chemical reaction heat (or energy). This energy, called additional dissociation energy due to intermolecular interactions between different organic compound molecules, may not be negligibly small, but instead may comprise a considerable part of the total energy.

As discussed in "Comparison of combustion heat values with theoretical reaction heat values", the intermolecular interactions could include hydrophobic interactions (HI), $\pi-\pi$ interactions, 
hydrogen bonding (HB), and van der Waals interactions (vdW) between the different organic compounds. Hydrophobic interactions are a special class of interaction representing associations of nonpolar groups in polar solvents. Functional groups of hydrophobic interaction include alkyl groups, ester groups, nitro groups, and so on (Dimitrijević et al. 2012). Aromatic $\pi-\pi$ interactions (sometimes called $\pi-\pi$ stacking interactions) occur between aromatic rings, often in situations where one is relatively electron rich and one is electron poor (Steed and Atwood 2000). Hydrogen bonds have the general motif $\mathrm{X}-\mathrm{H} \cdots \mathrm{Y}$, where the $\mathrm{X}-\mathrm{H}$ group is a proton donor and $\mathrm{Y}$ is a proton acceptor. Hydrogen bonds are highly directional non-covalent interactions with bond strength ranging from weak $(5-16.7 \mathrm{~kJ} / \mathrm{mol})$ to moderate $(16.7-62.7 \mathrm{~kJ} / \mathrm{mol})$ and even to strong $(83-167 \mathrm{~kJ} / \mathrm{mol}$ ) (Steiner 2002). Moderate hydrogen bonds are generally formed by neutral donor and acceptor groups, such as $-\mathrm{OH}$ and $-\mathrm{NH}$. In addition to intermolecular $\mathrm{O}-\mathrm{H} \cdots \mathrm{Y}$ $(\mathrm{Y}=\mathrm{O}, \mathrm{N})$ and $\mathrm{N}-\mathrm{H} \cdots \mathrm{Y}$ hydrogen bonds, a variety of weak $\mathrm{C}-\mathrm{H} \cdots \mathrm{Y}$ contacts could also be present (Dunitz and Gavezzotti 2009). Another type ofweak hydrogen bond in which $\pi$-systems play the role of acceptor, including $\mathrm{O}-\mathrm{H} \cdots \pi, \mathrm{N}-\mathrm{H} \cdots \pi, \mathrm{C}-\mathrm{H} \cdots \pi$, and $\mathrm{S}-\mathrm{H} \cdots \pi$ interactions, are also important in chemical systems (Saggu et al. 2012). Van derWaals interactions are driven by induced electrical interactions between two or more atoms or molecules that are very close to each other. This is the weakest of all intermolecular attractions, with interaction energies in the range of $2-8 \mathrm{~kJ} / \mathrm{mol}$ (Nangia 2010).

To have a good understanding of the molecular interactions present in mixtures, Table 3 shows the range of additional dissociation energies that can be attributed to each interaction. Using previously reported energy data, the possible interaction energies ignored by the semi-empirical equation were estimated using the most probable molecular interactions between different molecules of the six mixtures (Table 4). The six organic mixtures have different ranges of additional dissociation energy from the four possible intermolecular interactions. The percentage of additional dissociation energy to measured energy (combustion heat) was as follows: from 9.6 to $30.2 \%$ for mixture $1,11.8$ to $32.3 \%$ for mixture $2,7.7$ to $22.2 \%$ for mixture $3,6.7$ to $19.4 \%$ for mixture 4, 6.4 to $19.3 \%$ for mixture 5 , and 5.4 to $16.8 \%$ for mixture 6 . When more possible intermolecular interactions were used in the calculation, the additional dissociation energy accounted for a lower the percentage of the measured energy.

Table 3 Estimation of additional dissociation energies due to intermolecular interactions

\begin{tabular}{llll}
\hline $\begin{array}{l}\text { Intermolecular } \\
\text { interaction }\end{array}$ & $\begin{array}{l}\text { Chemical bond or } \\
\text { functional group }\end{array}$ & $\begin{array}{l}\text { Dissociation } \\
\text { energy, } \mathrm{kJ} / \mathrm{mol}\end{array}$ & References \\
\hline $\begin{array}{lll}\text { Hydrophobic interaction } \\
\pi-\pi \text { interaction }\end{array}$ & $-\mathrm{COO},-\mathrm{NO}_{2},-\mathrm{O}-,-\mathrm{CH}-,-\mathrm{CH}_{2}-,-\mathrm{CH}_{3}$ & $2-40$ & (Dimitrijević et al. 2012; Steed and Atwood 2000) \\
Hydrogen bonding & $\pi \cdots \pi$ & $8-50$ & (Mohan 2014; Nangia 2010) \\
& $\mathrm{X}-\mathrm{H} \cdots \mathrm{Y}(\mathrm{X} / \mathrm{Y}=\mathrm{O}, \mathrm{N})$ & $21-63$ & (Dunitz and Gavezzotti 2009; Nangia 2010; Steiner 2002) \\
& $\mathrm{C}-\mathrm{H} \cdots \mathrm{Y}(\mathrm{Y}=\mathrm{O}, \mathrm{N})$ & $13-25$ & (Dey and Ghosh 2014; Steiner 2002) \\
(Saggu et al. 2012; Scheiner 2015; Steiner 2002)
\end{tabular}


Table 4 Possible dissociation energies ignored by semiempirical calculation for chemical mixtures

\begin{tabular}{|c|c|c|c|c|c|c|}
\hline \multirow[t]{2}{*}{ Organic mixture } & \multicolumn{4}{|c|}{ Number of possible intermolecular interaction } & \multicolumn{2}{|c|}{ Additional dissociation energy } \\
\hline & $\mathrm{HI}$ & $\pi-\pi$ & HB & vdW & Estimation, $\mathrm{kJ} / \mathrm{L}$ & $\begin{array}{l}\text { Percent of the } \\
\text { measured energy }\end{array}$ \\
\hline 1 & 3 & 0 & 8 & 14 & $1692.9-5296.2$ & $9.6 \%-30.2 \%$ \\
\hline 2 & 1 & 0 & 6 & 11 & $2574.4-7064.4$ & $11.8 \%-32.3 \%$ \\
\hline 3 & 38 & 0 & 82 & 134 & $2417.7-6958.0$ & $7.7 \%-22.2 \%$ \\
\hline 4 & 40 & 0 & 86 & 140 & $2477.6-7170.6$ & $6.7 \%-19.4 \%$ \\
\hline 5 & 45 & 1 & 93 & 154 & $2453.2-7421.9$ & $6.4 \%-19.3 \%$ \\
\hline 6 & 68 & 2 & 131 & 224 & $2361.4-7329.2$ & $5.4 \%-16.8 \%$ \\
\hline
\end{tabular}

Additional dissociation energy was calculated as the sum of the energy from each intermolecular interaction. Inreality, energy from multiple interactions is often greater than the sum of the forces acting separately (positively cooperative) (Williams et al. 2004). The synergistic effects of noncovalent interactions are omnipresent in chemical and biological systems. Quiñonero et al. (2008) demonstrated that there is a certain interplay between $\pi-\pi$ and $\mathrm{X}-\mathrm{H} / \pi$ interactions $(\mathrm{X}=\mathrm{C}, \mathrm{N}, \mathrm{O})$ in complexes in which both interactions coexist. These synergistic effects are modest in magnitude for neutral molecules; nevertheless, their contribution to the total interaction energy is important. The interactions between different organic compounds and their synergistic effects in organic mixtures were ignored in the semi-empirical calculation of $--\Delta \mathrm{rH}_{\mathrm{se}}^{0}$. As shown in Tables 2 and 4, in the theoretical calculations of reaction heat, the hydrophobic interactions, $\pi-\pi$ interactions, hydrogen bonding, and van derWaals interactions (vdW) between different organic compounds were not accounted for mixtures 1 and 2. These interactions with their synergistic effects were also not accounted for in mixtures 3 to 6 in the theoretical calculations. The additional dissociation energy evaluated in Table 4 should have resulted in an increase in the combustion heat of the mixtures; therefore, $\mathrm{k}_{\mathrm{m}}=69.185 \mathrm{~kJ} / \mathrm{g}$ is the more suitable coefficient for entropy increase calculation in Eq. (6).

\section{Conclusions}

Calculating thermodynamic entropy can assist in quantitatively evaluating the impact of organic discharge into a water environment. Here, the decomposition of excess organic carbon to the background level demands energy consumption, resulting in an entropy increase in the aquatic system. According to the thermodynamic principles, the energy required for the oxidation of organics is equivalent to their combustion heat. By employing a direct measurement of the combustion heat of typical organic compounds, the linear relationship between $\Delta \mathrm{Sc}$ and $\Delta \mathrm{TOC}$ was experimentally verified, and the proportionality coefficient was determined to be the same as the semiempirical equation proposed in the authors' previous study. It can thus be concluded that for individual organic compounds of varied chemical structures, the energy required for their 
oxidation is mainly determined by the organic mass. Evaluating $\Delta \mathrm{Sc}$ is possible via TOC analysis of the discharged organic matter. However, the oxidation of organic mixtures may be a more complicated chemical process involving interactions between various functional groups of these organic components. This may inevitably bring about the consumption of additional dissociation energy, as indicated by the larger proportionality coefficient for mixtures in Eq. (6). The semiempirical method significantly underestimated the dissociation energy of organic mixtures; thus, improvements are required for predictions under environmentally relevant conditions. Organic matter in secondary effluent can be considered to be an organic mixture, so the modified $\Delta \mathrm{Sc}-$ $\Delta$ TOC relationship for organic mixtures should be adopted to replace the previously proposed semi-empirical equation for calculating the entropy increase.

\section{Acknowledgments}

This work was supported by the National Natural Science Foundation of China (no. 51508448), the National Program of Water Pollution Control (no. 2013ZX07310-001), the Program for

Innovative Research Team in Shaanxi Province (no. 2013KCT-13), and the collaborative research between Xi'an University of Architecture and Technology and University of Technology, Sydney.

\section{References}

Atkins P, de Paula J (2002) Physical chemistry. Oxford University Press, New York

Dey D, Ghosh S (2014) Quantitative evaluation of $\mathrm{C}-\mathrm{H} \cdots \mathrm{O}$ and $\mathrm{C}-\mathrm{H} \cdots \pi$ intermolecular interactions in ethyl-3-benzyl-1-methyl-2-oxoindoline-3- carboxylate and 3-methyl-but-2-en1-yl-1,3-dimethyl-2- oxoindoline-3-carboxylate: insights from PIXEL and Hirshfeld analysis. J Chem Crystallogr 44:131 - 142

Dimitrijević BP, Borozan SZ, Stojanović SĐ (2012) $\pi-\pi$ and cation $-\pi$ interactions in protein porphyrin complex crystal structures. RSC Adv 2:12963 - 12972

Dong MM, Trenholm R, Rosario-Ortiz FL (2015) Photochemical degradation of atenolol, carbamazepine, meprobamate, phenytoin and primidone in wastewater effluents. J Hazard Mater 282:216 - 223

Dunitz JD, Gavezzotti A (2009) How molecules stick together in organic crystals: weak intermolecular interactions. Chem Soc Rev 38(9): 2622 - 2633

Gadad P, Lei H, Nanny MA (2007) Characterization of noncovalent interactions between 6propionyl-2-dimethylaminonaphthalene (PRODAN) and dissolved fulvic and humic acids. Water Res 41(19):4488 - 4496

Gotovtsev AV (2010) Modification of the Streeter-Phelps system with the aim to account for the feedback between dissolved oxygen concentration and organic matter oxidation rate. Water Res 37(2):245 - 251 
Katsoyiannis A, Samara C (2007) The fate of dissolved organic carbon (DOC) in the wastewater treatment process and its importance in the removal of wastewater contaminants. Environ Sci Pollut Res 14(5):284 - 292

Lee CJ, Rasmussen TJ (2006) Occurrence of organic wastewater compounds in effluentdominated streams in northeastern Kansas. Sci Total Environ 371:258 - 269

Leenheer JA, Croué JP (2003) Characterizing dissolved aquatic organic matter. Environ Sci Technol 37(1):18A - 26A

Logar I, Brouwer R, MaurerM, Ort C (2014) Cost-benefit analysis of the Swiss National Policy on Reducing Micropollutants in Treated Wastewater. Environ Sci Technol 48(21):12500 12508

Lukas HL, Fries SG, Sundman B (2007) Computational thermodynamics: the Calphad method, 7th edn. Cambridge University Press, New York

Luo L, Wang XC, Guo WS, Ngo HH, Chen Z (2012) Impact assessment of extra discharges of organics and nutrients into aquatic systems by entropy calculation. J Environ Manag $112: 45-52$

Matilainen A, Sillanpää M (2010) Removal of natural organic matter from drinking water by advanced oxidation processes. Chemosphere 80:351 - 365

Mazzei P, Piccolo A (2015) Interactions between natural organic matter and organic pollutants as revealed by NMR spectroscopy. Magn Reson Chem 53:667 - 678. doi:10.1002/mrc.4209

Michael I, Michael C, Duan X, He X, Dionysiou DD, Mills MA, Fatta Kassinos D (2015) Dissolved effluent organic matter: characteristics and potential implications in wastewater treatment and reuse applications. Water Res 77:213 - 248

Mohan N (2014) Molecular electrostatics for probing hydrogen bonds, halogen bonds and lone pair- $\pi$ interactions and design of receptors for lone pair bearing molecules. Ph.D. Dissertation, Cochin University of Science and Technology, Kerala, India

Nangia A (2010) Supramolecular chemistry and crystal engineering. J Chem Sci 122(3):295 310

Nerngchamnong N, Yuan L, Qi DC, Li J, Thompson D, Nijhuis CA (2013) The role of van der Waals forces in the performance of molecular diodes. Nat Nanotechnol 8:113-118

Pramanik BK, Roddick FA, Fan L, Jenong S, Vigneswaran S (2015) Assessment of biological activated carbon treatment to control membrane fouling in reverse osmosis of secondary effluent for reuse in irrigation. Desalination 364:90 - 95

Quaranta ML, Mendes MD, MacKay AA (2012) Similarities in effluent organic matter characteristics from Connecticut wastewater treatment plants. Water Res 46:284 - 294

Quiñonero D, Frontera A, Escudero D, Ballester P, Costa A, Deyà PM (2008) MP2 study of synergistic effects between $\mathrm{X}-\mathrm{H} / \pi(\mathrm{X}=\mathrm{C}, \mathrm{N}, \mathrm{O})$ and $\pi-\pi$ interactions. Theor Chem Account 120:385 - 393

Saggu M, Levinson NM, Boxer SG (2012) Experimental quantification of electrostatics in X$\mathrm{H} \cdots \pi$ hydrogen bonds. J Am Chem Soc 134: 18986 - 18997 
Scheiner S (2015) Non-covalent forces. Springer, Dordrecht Shon HK, Vigneswaran S, Snyder SA (2006) Effluent organic matter (EfOM) in wastewater: constituents, effects, and treatment. Crit Rev Environ Sci Technol 36:327 - 374

Steed JW, Atwood JL (2000) Supramolecular chemistry. Wiley, Chichester Steiner T (2002) The hydrogen bond in the solid state. Angew Chem Int Ed 41:48 - 76

Thayanukul P, Kurisu F, Kasuga I, Furumai H (2013) Evaluation of microbial regrowth potential by assimilable organic carbon in various reclaimed water and distribution systems. Water Res 47:225 - 232

Tijani JO, Fatoba OO, Petrik LF (2013) A review of pharmaceuticals and endocrine-disrupting compounds: sources, effects, removal, and detections. Water Air Soil Pollut 224:1 - 29

Wang HB, Zhang YJ (2014) Mechanisms of interaction between polycyclic aromatic hydrocarbons and dissolved organic matters. J Environ Sci Heal A 49(1):78 - 84

Wang ST, Zhang XW, Wang ZW, Li XK, Ma J (2014) In-depth characterization of secondary effluent from a municipal wastewater treatment plant located in northern China for advanced treatment. Water Sci Technol 69(7):1482 - 1488

Wang XC, ZhangCM,Ma XY, Luo L (2015)Water cycle management: a new paradigm of wastewater reuse and safety control. Springer, Heidelberg

Wei LL, Zhao QL, Xue S, Chang CC, Tang F, Liang GL, Jia T (2009) Reduction of trihalomethane precursors of dissolved organic matter in the secondary effluent by advanced treatment processes. J Hazard Mater 169:1012 - 1021

Williams DH, Stephens E, O’ Brien DP, Zhou M (2004) Understanding noncovalent interactions: ligand binding energy and catalytic efficiency from ligand-induced reductions in motion within receptors and enzymes. Angew Chem Int Ed 43:6596 - 6616

Xue S, Zhao QL, Ma XP, Li FY, Wang J, Wei LL (2011) Comparison of dissolved organic matter fractions in a secondary effluent and a natural water. Environ Monit Assess 180: $371-383$

Yang XW, Chen SP, Gao SL, Li HY, Shi QZ (2002) Constrution of a rotating-bomb combustion calorimeter and measurement of thermal effects. Instrum Sci Technol 30(3):311 - 321 